\title{
Epitopes of Bordetella pertussis lipopolysaccharides as potential markers for typing of isolates with monoclonal antibodies
}

\author{
Karine Le Blay, ${ }^{1}$ Martine Caroff, ${ }^{1}$ Frédéric Blanchard, ${ }^{1}$ Malcolm B. Perry ${ }^{2}$ \\ and Richard Chaby ${ }^{1}$
}

Author for correspondence: Richard Chaby. Tel: +331694171 91. Fax: +33169853715.

e-mail: rchaby@pasteur.fr

1 Equipe 'Endotoxines',
URA-1116 du CNRS,
Université de Paris-Sud,
91405 Orsay, France
2 Institute for Biological
Sciences, National
Research Council of
Canada, Ottawa, Ontario,
Canada

\begin{abstract}
Three hybridomas (P1P3, D7 and 60.5) producing monoclonal antibodies (mAbs) against Bordetella pertussis lipopolysaccharide (LPS) were established. All reacted with the LPS from a typical, vaccine strain of B. pertussis (1414), but not with that of a variant strain (A100). Two of these MAbs (P1P3 and 60.5) cross-reacted with a B. bronchiseptica LPS; only one (P1P3) reacted with a B. parapertussis LPS. ELISA reactivities with intact LPSs, and defined partial structures covalently linked to bovine serum albumin, were compared. mAb 60.5 bound to the terminal region of a distal trisaccharide consisting of $N$ acetylated amino sugars. D7 reacted with a substructure which can be modified in the B. parapertussis and B. bronchiseptica LPSs by addition of a polymeric O-chain. P1P3 bound to a nonacetylated glucosamine substituted with L-glycero-D-manno-heptose, present in the 'core' of the B. pertussis LPS. These mAbs may be useful for rapid typing of Bordetella in clinical isolates.
\end{abstract}

Keywords: Bordetella bronchiseptica, Bordetella parapertussis, Bordetella pertussis, lipopolysaccharide, immunogenic epitopes

\section{INTRODUCTION}

Bordetella pertussis, the aetiological agent of whooping cough, expresses several antigenic proteins (pertussis toxin, adenylate cyclase, filamentous haemagglutinin) and, like all other Gram-negative bacteria, an 'endotoxin' which is actually a family of structurally related lipopolysaccharides (LPS). We established previously the existence of two types of variations in preparations of $B$. pertussis LPSs: one is due to the presence or absence of a phosphate group on a 3-deoxy-D-manno-2-octulosonic acid (Kdo) unit in the 'core' region (Le Dur et al., 1980), and the other is due to the presence or absence of a distal trisaccharide (Caroff et al., 1990). The latter finding explained the presence of two bands (designated A and B) in silver-stained SDS-PAGE of $B$. pertussis cell lysates (Peppler, 1984). The observation that LPSs from $B$. pertussis (Ackers \& Dolby, 1972; Mountzouros et al., 1992) and from other bacteria (Terashima et al., 1991) can elicit the production of protective antibodies, and the

Abbreviations: PeS, distal pentasaccharide isolated from the $B$. pertussis 1414 LPS; DiS, disaccharide isolated from the B.pertussis 1414 LPS. NA/LPS, LPS deaminated by nitrous acid treatment; HF/LPS, LPS dephosphorylated with hydrogen fluoride; i.p., intraperitoneally; i.v., intravenously. recent recrudescence of whooping cough in several developed countries, prompted us to produce anti-LPS monoclonal antibodies ( $\mathrm{mAbs}$ ) able to detect antigenic modifications in LPSs from variant $B$. pertussis strains, or from related Bordetella species ( $B$. parapertussis, $B$. bronchiseptica).

The production of $\mathrm{mAbs}$ to $B$. pertussis LPSs has been reported by various authors (Mountzouros et al., 1992; Frank \& Parker, 1984; Gustafsson et al., 1988; Li et al., 1988; Archambault et al., 1991; Martin et al., 1992). However, the characterization of the epitopes recognized by these $\mathrm{mAbs}$ was hampered by the absence of structural data on the antigens used. Our structural studies (Chaby \& Caroff, 1988; Lebbar et al., 1994; Di Fabio et al., 1992) of different Bordetella LPSs allowed us to re-examine this problem. In this paper we describe the production of $\mathrm{mAbs}$ that we used to characterize three antigenic epitopes of $B$. pertussis LPSs. These mAbs may be useful for the rapid screening and typing of clinical isolates.

\section{METHODS}

Chemicals and reagents. Polyoxyethylene-sorbitan monolaurate (Tween 20), 2,6,10,16-tetramethylpentadecane (pristane), horseradish-peroxidase-labelled goat anti-mouse Ig, 


\begin{tabular}{|c|c|}
\hline $\begin{array}{l}\text { LPS } \\
\text { Bp1414 }\end{array}$ & 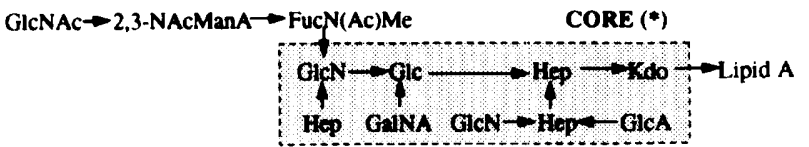 \\
\hline $\begin{array}{l}\text { LPS } \\
\text { BpA100 }\end{array}$ & $\operatorname{cose}(9)$ \\
\hline $\begin{array}{l}\text { LPS } \\
\text { B. bronchi }\end{array}$ & 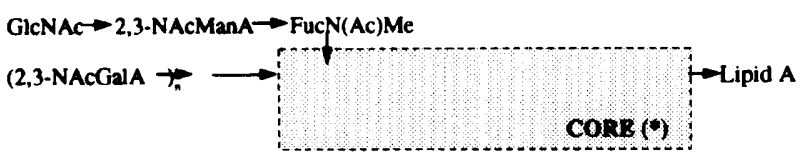 \\
\hline $\begin{array}{l}\text { LPS } \\
\text { B. para }\end{array}$ & $(2,3-\mathrm{NACGalA} \rightarrow \longrightarrow$ \\
\hline $\begin{array}{l}\text { NA/LPS } \\
\text { Bp1414 }\end{array}$ & $\underset{\text { Glc } \rightarrow \text { Hep } \longrightarrow \text { HlcA }}{\rightarrow} \rightarrow$ Kdo $\rightarrow$ Lipid A \\
\hline PeS-BSA & GlcNAc $\rightarrow$ 2,3-NACManA $\rightarrow$ FucN(Ac)Me \\
\hline DiS-BSA & $\begin{aligned} 2,3-\mathrm{NACManA} & \rightarrow \underset{\mathrm{fuCN}(\mathrm{AC}) \mathrm{Me}}{ } \\
\mathrm{O}-\mathrm{CH}, \mathrm{CHOH}-\mathrm{CH}, \longrightarrow & \longrightarrow \mathrm{BSA}\end{aligned}$ \\
\hline GICNAC-BSA & GlcNAc $\rightarrow$ [cysteamine/glutandelehyde arm] $\longrightarrow$ BSA \\
\hline
\end{tabular}

Fig. 1. Putative structures of the antigens used. LPSs Bp1414, BpA100, B. bronchi. and B. para., LPSs from $B$. pertussis strain 1414, $B$. pertussis strain A100, B. bronchiseptica strain NRCC 4170 and $B$. parapertussis strain ATCC 15989, respectively. NA/LPS Bp1414, nitrous-acid-deaminated LPS Bp1414. GlcNacBSA, DiS-BSA, and PeS-BSA, conjugates consisting of BSA covalently coupled to GICNAC, or to the indicated disaccharide and pentasaccharide, respectively. FucN(Ac)Me, $N$-acetyl- $N$-methylfucosamine. GalNA, galactosaminuronic acid; Glc, glucose; GICA, glucuronic acid; GIcN, glucosamine; GIcNAc, $\mathrm{N}$-acetylglucosamine; Hep, heptose; Kdo, 3deoxy-D-manno-2-octulosonic acid; Man, mannose; 2,3-NAcGalA, 2,3-dideoxy-2,3-di$\mathrm{N}$-acetylgalacturonic acid; 2,3-NAcManA, 2,3-dideoxy-2,3-di- $N$-acetylmannuronic acid. (*) Phosphate and phosphorylethanolamine groups, present in all LPS preparations, are not represented. Unpublished studies suggest that the core of LPS B. bronchi. is substituted with at least one phosphate group, and that the core of LPS B. para. is shorter than that of LPS Bp1414. The results obtained in the present study also suggest that the core of LPS BpA100 contains one (or more) HF-labile residue(s). anti-mouse $\mathrm{H}$ chain of different classes and subclasses, and the peroxidase substrates 0 -phenylenediamine dihydrochloride and 3,3'-diaminobenzidine were from Sigma. Polyisobutyl methacrylate was from Aldrich, gelatin from Rousselot Kuhlmann, and polyethylene glycol 1500 from Boehringer.

Lipopolysaccharides. The $B$. pertussis LPSs from the vaccine strain 1414, and from the variant strain A100, were isolated by the phenol/water extraction procedure, and purified as described previously (Le Dur et al., 1980; Caroff et al., 1990). The LPSs from B. parapertussis (strain ATCC 15989 from the American Type Culture Collection) and B. bronchiseptica (strain NRCC 4170 from the National Research Council Veterinary Collection) were prepared by extraction of the cells by the modified enzyme/phenol/water method and ultracentrifugation of the concentrated, dialysed, aqueous phases $\left(105000 \mathrm{~g}, 4^{\circ} \mathrm{C}, 12 \mathrm{~h}\right.$ ) (Johnson \& Perry, 1976). The putative structures of these four LPSs, based on previously published (Chaby \& Caroff, 1988; Lebbar et al., 1994; Di Fabio et al., 1992) or as yet unpublished studies (M. Caroff, D. Karibian, H. Zarrouk, J. C. Richards and M. B. Perry), are indicated in Fig. 1.

Analyses. The heptose content of the preparations was determined by quantitative estimation of heptitol acetate by GLC, after acid hydrolysis $\left(2 \mathrm{M} \mathrm{HCl}, 2 \mathrm{~h}, 100^{\circ} \mathrm{C}\right)$ of the preparations, further reduction $\left(1 \mathrm{M} \mathrm{NaBH}, 4 \mathrm{~h}, 20^{\circ} \mathrm{C}\right)$ of the sugars, and peracetylation of their alditols. Methylations, acetylations and GLC analyses $(25 \mathrm{~m} \times 0.32 \mathrm{~mm}$ capillary column coated with a
BP 10 bonded phase) were carried out as described previously (Caroff et al., 1990).

Cleavage of LPSs with nitrous acid. The LPSs from the $B$. pertussis strains 1414 (LPS Bp1414) and A100 (LPS BpA100) were incubated $\left(5 \mathrm{~g} \mathrm{l}^{-1}\right)$ for $4 \mathrm{~h}$ at $20^{\circ} \mathrm{C}$ in a freshly prepared mixture of water $/ 5 \%(\mathrm{w} / \mathrm{v})$ sodium nitrite $/ 30 \%(\mathrm{v} / \mathrm{v})$ acetic acid (1:1:1, by vol.), as described previously (Caroff et al., 1990; Deprun et al., 1993). The suspensions were ultracentrifuged (200000 $g$ for $2 \mathrm{~h}$ ) and the fragments containing the Kdo-lipid A region (NA/LPS Bp1414 and NA/LPS BpA100) were isolated in the pellets. If TLC (solvent $A$; see below) indicated incomplete deaminative cleavage, the pellet was treated with nitrous acid for a second time. The structure of NA/LPS Bp1414 is given in Fig. 1. The distal pentasaccharide fragment (PeS) released from LPS Bp1414 during treatment with nitrous acid was isolated from the corresponding supernatant by chromatography on a Bio-Gel P2 column (Bio-Rad) eluted with water. Analyses of the PeS preparation by TLC (solvent B) (Caroff \& Karibian, 1990) showed no detectable contaminants.

Preparation of the PeS-BSA conjugate. The PeS isolated by nitrous acid deamination of LPS Bp1414 was directly coupled to BSA by reductive amination, as described by Roy et al. (1984). Briefly, PeS $(5 \mathrm{mg})$ was incubated for $48 \mathrm{~h}$ at $37^{\circ} \mathrm{C}$ with BSA $(10 \mathrm{mg})$ and sodium cyanoborohydride $(20 \mu \mathrm{mol})$ in $0.2 \mathrm{M}$ phosphate buffer $(1 \mathrm{ml}, \mathrm{pH})$. After neutralization with acetic acid, the solution was made up to $0.15 \mathrm{M} \mathrm{NaCl}$ and the conjugate was separated from uncoupled polysaccharide by 
chromatography on a Sephadex G-150 column. Elution was monitored by absorption at $220 \mathrm{~nm}$. The purified PeS-BSA conjugate $(3.6 \mathrm{mg})$ contained $10 \%(\mathrm{w} / \mathrm{w})$ PeS according to its heptose content. The structure of PeS-BSA is indicated in Fig. 1.

Dephosphorylation by HF treatment. LPS Bp1414, LPS BpA100 and NA/LPS BpA100 $\left(10 \mathrm{~g} \mathrm{l}^{-1}\right)$ were incubated in aqueous $\mathrm{HF}(50 \%, \mathrm{v} / \mathrm{v})$ at $4{ }^{\circ} \mathrm{C}$ for $48 \mathrm{~h}$ in sealed polyethylene tubes (Lipkin et al., 1969). After removal of HF under a stream of nitrogen at room temperature, the dried residues were dissolved in water and dialysed against distilled water. HF/LPS Bp1414, HF/LPS BpA100 and HF-NA/LPS BpA100 were recovered by lyophilization.

Preparation of the DiS-BSA conjugate. After hydrolysis of a $1.5 \%(\mathrm{w} / \mathrm{v})$ solution of HF/LPS Bp1414 in sodium acetate $(\mathrm{pH}$ 4.5 ) for $2 \mathrm{~h}$ at $100{ }^{\circ} \mathrm{C}$ in the presence of $1 \%$ (w/v) SDS (Caroff et al., 1988), the polysaccharide fragment (HF/PS) was isolated by chromatography on a Sephadex G-50 column. Smith degradation of $\mathrm{HF} / \mathrm{PS}$ was carried out by incubations $\left(20^{\circ} \mathrm{C}\right)$ of an aqueous solution $\left(4 \mathrm{~g} \mathrm{l}^{-1}, 33 \mathrm{ml}\right)$ of the polysaccharide with $0.7 \mathrm{mM}$ sodium periodate $(48 \mathrm{~h}), 15 \mathrm{mM}$ ethylene glycol $(15 \mathrm{~min}), 75 \mathrm{mM}$ sodium borohydride $(18 \mathrm{~h})$, and $0 \cdot 1 \mathrm{M}$ acetic acid $(1 \mathrm{~h})$, successively. The material was desalted by filtration (Diaflow YC 05 membrane, Amicon) and submitted to chromatography on a Biogel P2 column eluted with water. The fragment consisting of the disaccharide 2,3-NAcManAFucN(Ac)Me-erythritol (DiS), identified by NMR analysis (data not shown) was isolated and lyophilized. The erythritol unit of DiS was oxidized by incubation of $3.65 \mathrm{mg}$ DiS for $20 \mathrm{~min}$ at $20^{\circ} \mathrm{C}$ in $0.7 \mathrm{mM}$ sodium periodate. The reaction was stopped by further incubation (15 min) with $15 \mathrm{mM}$ ethylene glycol. The oxidized material was incubated $\left(48 \mathrm{~h}, 37^{\circ} \mathrm{C}\right)$ with BSA $(10 \mathrm{mg})$ and radiolabelled sodium cyanoborohydride (185 MBq, $3.6 \mathrm{mg})$ in a $0.2 \mathrm{M}$ phosphate buffer $(1 \mathrm{ml}, \mathrm{pH} 8)$. The radiolabelled conjugate was isolated by chromatography on a Sephadex G150 column. The structure of the DiS-BSA conjugate is indicated in Fig.1.

Preparation of the GICNAC-BSA conjugate. $N$-Acetylglucosamine- $\beta$-allyloside was synthesized by $\mathrm{Dr} \mathrm{D}$. Charon (Châtenay-Malabry, France). Covalent coupling to cysteamine (Roy et al., 1984; Lee \& Lee, 1974) was performed by incubation $\left(18 \mathrm{~h}, 20^{\circ} \mathrm{C}\right)$ of a $2 \mathrm{M}$ solution of this compound with a $7 \cdot 7 \mathrm{M}$ solution of cysteamine hydrochloride. The propylaminoethanethiol derivative of GlcNAc was isolated by chromatography on a column of AG $50 \mathrm{WX} 8(\mathrm{H}+)$ resin, eluted with $0.1 \mathrm{M}$ ammonium hydroxide. The purified compound $(42 \%$, $\mathrm{w} / \mathrm{w}$, yield) was covalently coupled to BSA by the glutaraldehyde method (Avrameas, 1969). The GlcNAc-BSA conjugate (Fig. 1) was dialysed and lyophilized. The accessibility of GlcNAc units on the conjugate was demonstrated in preliminary experiments (data not shown) by the binding of radiolabelled wheat germ agglutinin, a lectin which interacts with $N$-acetyl-Dglucosamine units (Sharon \& Lis, 1972).

Animal immunizations. Groups of four BALB/c mice ( $R$. Janvier, Le Genest Saint-Isle, France) were immunized at $14 \mathrm{~d}$ intervals with $B$. pertussis LPS $\left(1 \mu \mathrm{g} \mathrm{ml}^{-1}\right.$, i.p.), or with phenolkilled and lyophilized $B$. pertussis cells $\left(1 \mathrm{mg} \mathrm{ml} \mathrm{m}^{-1}\right.$, i.v.). Each preparation was suspended in $200 \mu$ nonpyrogenic $0.15 \mathrm{M} \mathrm{NaCl}$ solution (Biosedra, Malakoff, France). Sera were collected $7 \mathrm{~d}$ after each injection.

Production of mAbs. The mouse which produced the highest titre of anti-LPS antibodies (detected after the second immunization) was selected for fusion. Three days after the last injection, the spleen cells were fused at a 10:1 ratio with SP2/0-
Ag. 14 myeloma cells, in $45 \%(\mathrm{w} / \mathrm{v}$ ) polyethylene glycol 1500 , as described previously (Girard \& Chaby, 1985). Fusion products were cultured in a hypoxanthine/azaserine $(50 \mu \mathrm{M}: 10 \mu \mathrm{M})$ selection medium. Resulting colonies were tested for secretion of anti-LPS antibodies, and cloned by limiting dilution (Nowinsky et al., 1979). Clones were expanded as ascites by injection $\left(5 \times 10^{6}\right.$ cells per mouse, i.p.) in BALB/c mice treated with pristane $(0.5 \mathrm{ml}$, i.p.) two weeks previously.

ELISA. Sera and cell culture supernatants were assayed for antiLPS or anti-BSA-conjugate antibodies by ELISA. The 96-well Immulon-A plates (Greiner Labortechnik) were coated with the antigen $\left(100 \mu \mathrm{l}\right.$ of $20 \mu \mathrm{g} \mathrm{ml}^{-1}$ suspensions in $50 \mathrm{mM}$ Tris/ $\mathrm{HCl}$ buffer plus $20 \mathrm{mM} \mathrm{MgCl}_{2}, \mathrm{pH} 9 \cdot 6$ ). After overnight incubation at $20^{\circ} \mathrm{C}$ with gentle stirring, the unbound antigen was washed away with $0.1 \%$ Tween 20 in PBS (Tween buffer), and the plates were incubated for $1 \mathrm{~h}$ at $37^{\circ} \mathrm{C}$ with $0.25 \%$ (w/v) gelatin in the same buffer. The plates were rewashed with this solution and the sample of serum or culture supernatant (diluted in the same solution) added to each well. After incubation for $2 \mathrm{~h}$ at $37^{\circ} \mathrm{C}$, the plates were washed with the Tween buffer, and the peroxidase-labelled goat anti-mouse Ig reagent added. After incubation at $37^{\circ} \mathrm{C}$ for $90 \mathrm{~min}$, the plates were washed and developed by adding $100 \mu \mathrm{l}$ of a freshly prepared solution of 0 phenylenediamine $\left(0.5 \mathrm{mg} \mathrm{ml}^{-1}\right)$ in $0.05 \mathrm{M}$ phosphate/citrate buffer ( $\mathrm{pH}$ 5) containing sodium perborate $(0.03 \%, \mathrm{w} / \mathrm{v})$ as a substitute for hydrogen peroxide. After $15 \mathrm{~min}$ at room temperature, the reaction was stopped with a solution of $0.5 \%$ (w/v) sodium sulfite in $1 \mathrm{M} \mathrm{H}_{2} \mathrm{SO}_{4}(50 \mu \mathrm{l}$ per well). The plates were scanned at $490 \mathrm{~nm}$ in a Dynatech MR 5000 spectrophotometer. Antibody isotypes were determined by the same ELISA procedure, by using peroxidase-labelled goat antibodies against mouse Ig of different classes and subclasses.

TLC and immunostaining. TLC of LPSs (1-2 $\mu \mathrm{g}$ per lane) was carried out on Silica gel $60(0.2 \mathrm{~mm}$ on aluminium foil; Merck) in solvent $\mathrm{A}$ (isobutyric acid/1 $\mathrm{M}$ ammonium hydroxide, $5: 3$, $\mathrm{v} / \mathrm{v}$ ) (Caroff \& Karibian, 1990). Polysaccharides were analysed by TLC in solvent $B$ (isobutyric acid/1 $\mathrm{M}$ ammonium hydroxide, 3:5, v/v). LPS and polysaccharide spots were revealed by heating $\left(120^{\circ} \mathrm{C}\right)$ the plates with $10 \%(\mathrm{v} / \mathrm{v})$ sulfuric acid in ethanol. For immunostaining, the plates were dried after chromatography, and dipped for $2 \mathrm{~min}$ in a solution of polyisobutylmethacrylate $(0 \cdot 1 \%$ in hexane/acetone; $99: 1, \mathrm{v} / \mathrm{v})$. The plates were dried again and saturated $\left(1 \mathrm{~h}, 37^{\circ} \mathrm{C}\right)$ with lowfat lyophilized milk $(5 \%, \mathrm{w} / \mathrm{v}$, in PBS). After three washings ( $5 \mathrm{~min}, 20^{\circ} \mathrm{C}$, with gentle stirring) in a washing buffer consisting of milk $(5 \%, \mathrm{w} / \mathrm{v})$ and Tween $20(0 \cdot 1 \%)$ in PBS, the plates were overlaid with one of the anti-LPS mAbs (undiluted cell culture supernatant of the corresponding hybridoma), incubated for $2 \mathrm{~h}$ at $37^{\circ} \mathrm{C}$ with gentle shaking, and washed (three times, $5 \mathrm{~min}$ each) with the washing buffer. The plates were further incubated $\left(1 \mathrm{~h}, 37^{\circ} \mathrm{C}\right)$ with a peroxidase-labelled goat anti-mouse Ig reagent $(1 / 1000$ dilution), washed again, and developed (5$10 \mathrm{~min}, 20^{\circ} \mathrm{C}$ ) in a freshly prepared solution of diaminobenzidine $\left(0.5 \mathrm{~g} \mathrm{l}^{-1}\right)$ in phosphate/citrate buffer ( $\left.\mathrm{pH} 5\right)$ containing sodium perborate $(0.03 \%)$. The reaction was stopped by addition of acetic acid $(0.1 \mathrm{ml} \mathrm{AcOH}$ in $20 \mathrm{ml}$ of the substrate solution).

\section{RESULTS}

\section{Antibody response to LPS in vivo}

In a preliminary experiment, mice were injected, at $14 \mathrm{~d}$ intervals, with the $B$. pertussis LPS. Sera were collected $7 \mathrm{~d}$ after each injection, and analysed by ELISA for their 


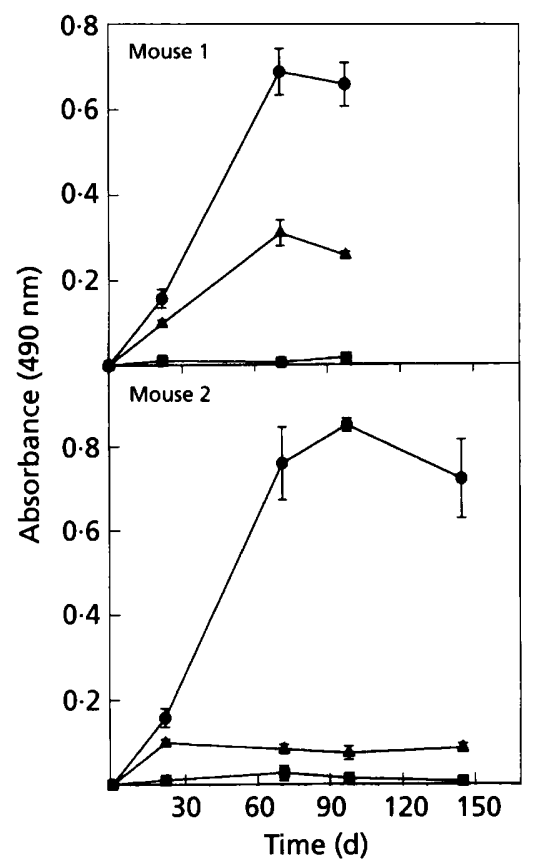

Fig. 2. Reactivity of mouse sera with different Bordetella LPSs. Two BALB/C mice (female, 5 weeks old) were immunized (i.p.) four times (mouse 1) or five times (mouse 2) with suspensions of LPS Bp1414 in saline $\left(200 \mu \mathrm{l}, 1 \mu \mathrm{g} \mathrm{ml}^{-1}\right)$. Sera were collected $7 \mathrm{~d}$ after each injection. Reactivities with the LPSs from $B$. pertussis $1414(0)$, B. pertussis A100 ( $(\mathbb{)}$ ) and B. bronchiseptica (A) were determined by ELISA. Values represent the mean \pm SD of triplicate determinations.

reactivities with the immunizing LPS (Bp1414), and with LPSs from other Bordetella strains (BpA100, B. bronchiseptica). The results obtained with two representative mice (Fig. 2) show that a marked reactivity with the homologous LPS (Bp1414) was always obtained after the third injection, whereas none of the sera reacted with the variant strain A100 of B. pertussis, even after prolonged immunizations. Reactivities of sera with the $B$. bronchiseptica LPS were more variable: some sera (like those from mouse 1) reacted with this LPS, whereas others (like those from mouse 2) did not. These results show that although the three LPSs share some common substructures (Fig. 1), the immunogenicities of these substructures in mice are very different.

\section{Production of hybridomas and ascitic fluids}

Mice were injected, at $14 \mathrm{~d}$ intervals, either with phenolkilled B. parapertussis cells, or with B. pertussis LPS. Fusion experiments were performed $3 \mathrm{~d}$ after the second injection with animals immunized with killed cells, and $3 \mathrm{~d}$ after the fifth injection with animals immunized with LPS. Hybridomas were first screened for their reactivity with the LPS preparation used for immunization, and then rescreened for the absence of cross-reactivity with a lipid A preparation obtained from the $B$. pertussis LPS. Among the remaining hybridomas, three clones of high reactivity
Table 1. mAbs produced after different immunizations

\begin{tabular}{|c|c|c|c|}
\hline \multicolumn{2}{|c|}{$\mathbf{m A b}$} & \multicolumn{2}{|c|}{ Immunization } \\
\hline Name & Class & $\begin{array}{c}\text { Material } \\
\text { injected* }\end{array}$ & Injections $\dagger$ \\
\hline P1P3 & $\operatorname{IgM}$ & LPS & 5 (i.p.) \\
\hline D7 & $\operatorname{IgG} 3$ & LPS & 5 (i.p.) \\
\hline 60.5 & $\operatorname{IgM}$ & Cells & 2 (i.v.) \\
\hline
\end{tabular}

* LPS, $1 \mu \mathrm{g} \mathrm{ml}^{-1}$; cells, $1 \mathrm{mg} \mathrm{ml}^{-1}$. $\nmid 200 \mu \mathrm{l}$, at $14 \mathrm{~d}$ intervals.

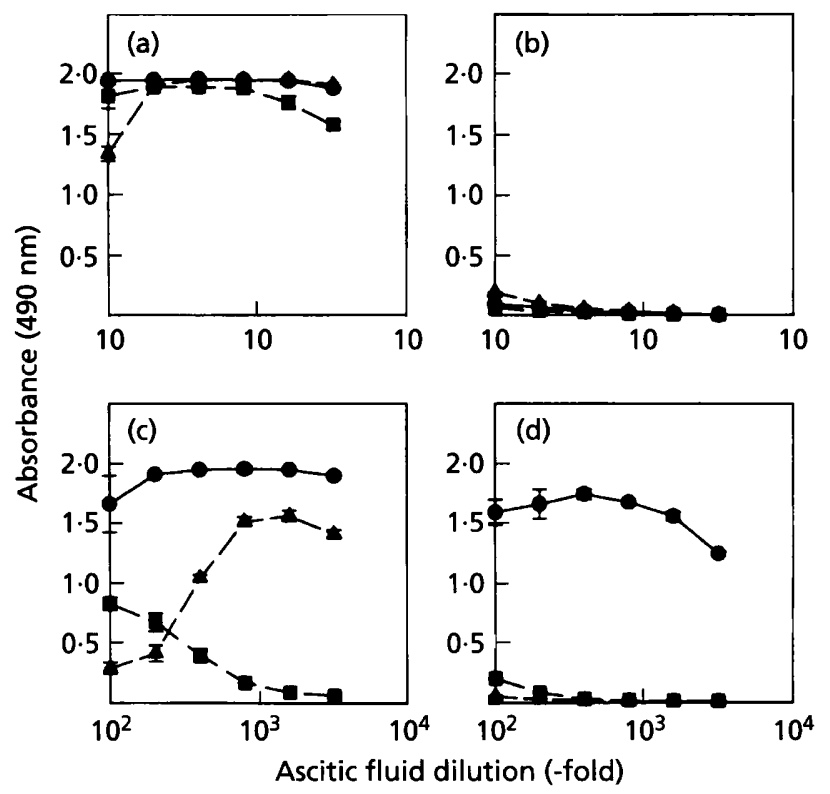

Fig. 3. Reactivity of mAbs $P 1 P 3, D 7$ and 60.5 with different Bordetella LPSs. Plates coated with the LPSs from $B$. pertussis 1414 (a), B. pertussis A100 (b), B. bronchiseptica (c) and B. parapertussis (d) were incubated with different dilutions of ascitic fluids from clones P1P3 (O), D7 ( $(\boldsymbol{D})$ and $60.5(\boldsymbol{A})$. The binding of the mAbs was determined by ELISA. Values represent the mean $\pm S D$ of triplicate determinations.

with LPS were selected for this study (Table 1). One clone (60.5) was produced with a mouse immunized with killed B. pertussis organisms, and two clones (P1P3 and D7) were obtained with mice immunized with the $B$. pertussis LPS. Analyses of the isotypes of the mAbs prepared from ascitic fluids indicated that $\mathrm{P} 1 \mathrm{P} 3$ and 60.5 are $\operatorname{IgM}$, whereas D7 is an IgG3 (Table 1).

\section{Reactivity of the mAbs with unmodified Bordetella LPSs}

The specificities of the three $\mathrm{mAbs}$ were analysed by their ability to interact with the LPSs from $B$. pertussis 1414, $B$. pertussis A100, B. bronchiseptica and B. parapertussis. Results obtained by ELISA (Fig. 3) showed clearcut differences in the specificities of these mAbs. All three mAbs reacted 


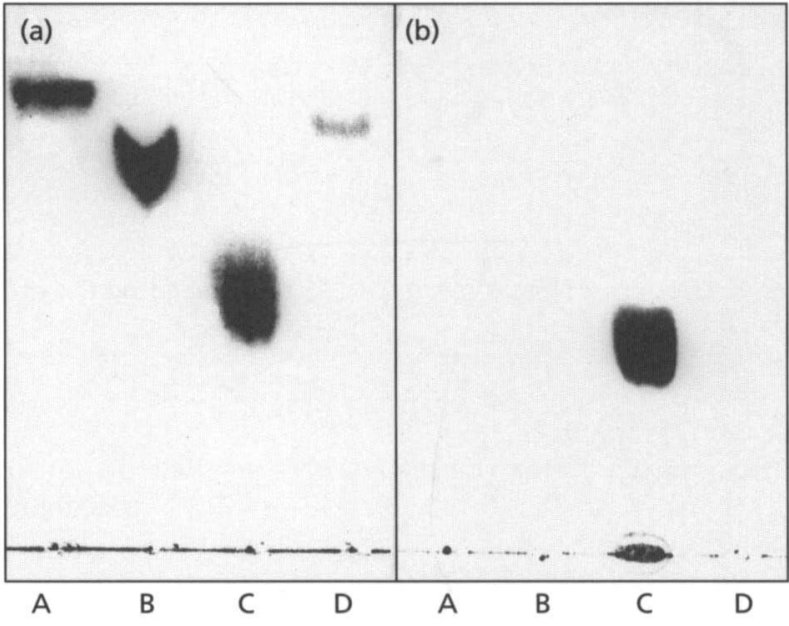

Fig. 4. Analysis of different LPSs by TLC. LPSs from $S$. minnesota Rd1 (A), S. typhimurium Rc (B), B. pertussis 1414 (C), and the nitrous-acid-treated LPS from $B$. pertussis 1414 (D) were analysed by TLC in isobutyric acid/1 M ammonium hydroxide $(5: 3, v / v)$. LPS bands were revealed by charring with sulfuric acid (a) or by immunostaining with mAb P1P3 (b).

with LPS Bp1414 (Fig. 3a), whereas only two of them ( $\mathrm{mAbs} \mathrm{P} 1 \mathrm{P} 3$ and 60.5 ) interacted with the B. bronchiseptica LPS (Fig. 3c), and only one (mAb P1P3) reacted with the $B$. parapertussis LPS (Fig. 3d); none of the three mAbs could recognize LPS BpA100 (Fig. 3b). These results clearly show that although the three mAbs interact with similar intensities with the LPS from strain 1414 of $B$. pertussis, they do so by binding to distinct epitopes.

\section{Reactivity of the mAbs with rough-type LPSs}

We established previously (Caroff et al., 1990) that a rough-type LPS consisting of a pentasaccharide linked to lipid A (NA/LPS Bp1414) can be isolated from the nitrous-acid-treated LPS of $B$. pertussis 1414 (Fig. 1). The reactivity of mAb P1P3 with NA/LPS Bp1414 was compared to its reactivity with untreated LPS Bp1414, and with rough-type LPSs from Salmonella ( $S$. minnesota $\mathrm{Rd} 1$ and $S$. typhimurium $\mathrm{Rc}$ ). Reactivities were analysed by immunostaining the LPS bands after migration on TLC. The results (Fig. 4) show that $\mathrm{mAb} \mathrm{P} 1 \mathrm{P} 3$ reacted exclusively with the untreated LPS Bp1414, but reacted neither with NA/LPS Bp1414, nor with the rough LPSs from Salmonella. Identical results (not shown) were obtained with the two other mAbs, 60.5 and D7. These results demonstrate that the mAbs interact neither with the Kdo-lipid A region of the LPSs, nor with the four other sugar units which are vicinal to this region in LPS Bp1414 (GlcA-Hep-Hep, Glc).

\section{Reactivity of mAb P1P3 with HF-treated LPS BpA100}

The absence of reactivity of P1P3 with the short-chain lipopolysaccharides LPS BpA100 (Fig. 3) and NA/LPS Bp1414 (Fig. 4) could suggest that this mAb reacts with distal carbohydrate units present only in Bordetella LPSs

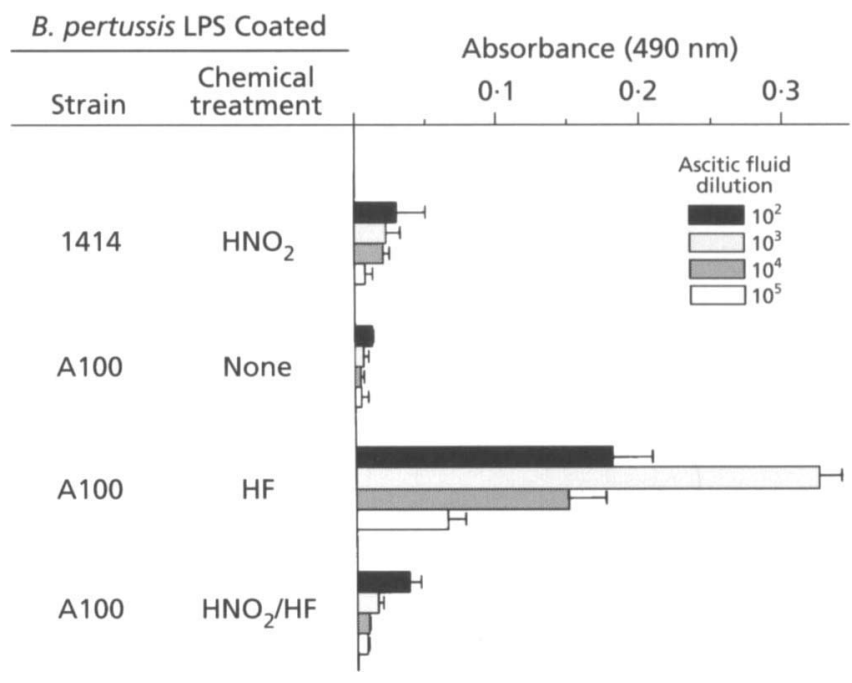

Fig. 5. Reactivity of mAb P1P3 with chemically modified $B$. pertussis LPSs. Plates coated with LPSs from $B$. pertussis strain 1414 or $A 100$, treated with nitrous acid and/or HF, were incubated with different dilutions of the ascitic fluid from clone P1P3. The binding of the mAb was determined by ELISA. Values represent the mean \pm SD of triplicate determinations.

with longer chains. Another experiment (Fig. 5), which confirmed this observation, provided an additional and unexpected result: after treatment of LPS BpA100 with $\mathrm{HF}$, the isolated material (HF/LPS-BpA100) was recognized by $\mathrm{mAb} \mathrm{P} 1 \mathrm{P} 3$, whereas the material obtained after sequential treatments with nitrous acid and HF (NAHF/LPS BpA100) was no longer recognized by P1P3 (Fig. 5). These results suggest (1) that the epitope recognized by $\mathrm{P} 1 \mathrm{P} 3$ is released during nitrous acid treatment, and (2) that an HF-labile substituent modifies this epitope in the variant A100 strain of B. pertussis.

\section{Reactivity of the mAbs with carbohydrate substructures coupled to BSA}

The reactivities of the mAbs with distal carbohydrate substructures were analysed with conjugates consisting of the terminal monosaccharide GlcNAc, the disaccharide $\mathrm{DiS}$, and the pentasaccharide PeS, covalently coupled to $\mathrm{BSA}$. The reactivities of the three $\mathrm{mAbs}$ with these conjugates, and with unmodified BSA, were determined by ELISA. The results (Fig. 6) show that none of the $\mathrm{mAbs}$ reacted with BSA and DiS-BSA. Only one $\mathrm{mAb}$ (60.5) reacted with GlcNAc-BSA. The conjugate PeSBSA, which carries the larger oligosaccharide substructure, was recognized by both $\mathrm{P} 1 \mathrm{P} 3$ and 60.5 . A significant but much lower reactivity was also observed with $\mathrm{mAb}$ D7.

\section{DISCUSSION}

The aim of the present study was to produce mAbs against distinct epitopes of the $B$. pertussis LPS that can potentially recognize the expression of atypical forms of 


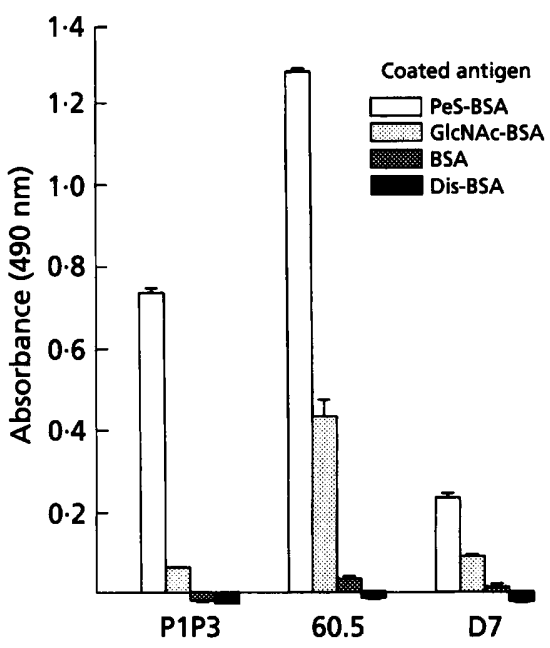

Fig. 6. Reactivity of mAbs $P 1 P 3,60.5$ and $D 7$ with different BSA-conjugates. Plates coated with PeS-BSA, GICNAC-BSA, DiS$B S A$, or BSA alone, were incubated with ascitic fluids (dilution $1 / 100$ ) from clones P1P3, 60.5 and $D 7$. The binding of the mAbs was determined by ELISA. Values represent the mean $\pm S D$ of triplicate determinations.

the LPS in variant strains of this bacterium. After immunization of mice with the LPS from $B$. pertussis strain 1414, three mAbs, termed 60.5, D7 and P1P3 were produced.

The specificity of $\mathrm{mAb} 60.5$ can be easily established. This $\mathrm{mAb}$ reacted with the LPSs from $B$. pertussis 1414 and $B$. bronchiseptica, but not with the LPSs from B. pertussis A100 and B. parapertussis (Fig. 3). The only structure present in the two former and absent from the two latter LPSs is the distal trisaccharide GlcNAc $\rightarrow$ 2,3-NAcManA $\rightarrow$ FucN(Ac)Me. The reactivity of 60.5 with the GlcNAcBSA conjugate (Fig. 6) confirms this assumption and shows that the epitope recognized by $\mathrm{mAb} 60.5$ consists of the terminal unit(s) of this distal trisaccharide (Fig. 7). The reactivity of 60.5 with GlcNAc-BSA is, however, markedly lower than that obtained with the intact L.PS. This may suggest that the presence of the next carbohydrate unit (2,3-NAcManA) can optimize the reactivity, and thus may be partially involved in the recognized epitope.

The specificity of mAb D7 can also be deduced from the data in Figs 3 and 6.D7 reacts strongly with the $B$. pertussis 1414 LPS, reacts only at high concentrations with the $B$. bronchiseptica LPS, and does not react with the $B$. parapertussis LPS. This means that the presence of the $\mathrm{O}-$ side chain, consisting of 2,3-NAcGalA repeating units, blocks the reactivity of D7 and thus modifies the epitope recognized by this $\mathrm{mAb}$. The low reactivity of $\mathrm{D} 7$ with the PeS-BSA conjugate and with the B. bronchiseptica LPS shows, however, that the presence of the distal trisaccharide slightly enhances the reactivity of D7. Taken together, these results indicate that the epitope recognized by $\mathrm{D} 7$ is affected by the addition of the O-side chain and that a portion of the distal trisaccharide could be involved
60.5

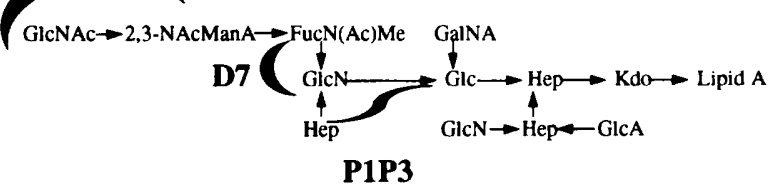

Fig. 7. Epitopes of the $B$. pertussis LPS recognized by the mAbs P1P3, D7 and 60.5.

in this epitope. This suggests therefore that this epitope may consist of the FucN(Ac) Me $\rightarrow$ GlcN disaccharide (Fig. 7).

The third $\mathrm{mAb}, \mathrm{P} 1 \mathrm{P} 3$, reacted with a substructure shared by the LPSs of three conventional strains of Bordetella: $B$. pertussis 1414, B. bronchiseptica and B. parapertussis (Fig. 3), thus indicating that the $\mathrm{O}$-chain is not involved in this reaction. The reactivity of $\mathrm{P} 1 \mathrm{P} 3$ with the $B$. parapertussis LPS, and with the HF-treated LPS from B. pertussis A100 (HF/LPS-BpA100), shows that P1P3 does not react with the distal trisaccharide, which is absent from these two LPSs. Therefore, the epitope recognized by P1P3 is apparently located in the common 'core' structure (Fig. 1). The absence of reactivity of P1P3 with the rough-type fragment (NA/LPS Bp1414) isolated after nitrous acid cleavage (Fig. 4) indicated that the epitope is localized in the terminal sugar units of the core which are released during nitrous deamination (GlcN, GalNA, or Hep $\rightarrow$ GlcN). The interaction of P1P3 with the PeS-BSA conjugate (Fig. 6) demonstrated that the epitope is a part of the Hep $\rightarrow$ GlcN moiety, which is the only substructure present in both the PeS-BSA HF/LPS-BpA100. However, the epitope recognized by P1P3 cannot be the terminal heptose alone, since P1P3 does not react with the rough-type LPS from $S$. minnesota $\mathrm{Rd1}$ (Fig. 4), which contains a terminal unsubstituted heptose unit. Therefore, we suggest that a region of the glucosamine unit to which the terminal heptose is attached also contributes to the epitope recognized by $\mathrm{mAb}$ P1P3. The carbon atoms 3,4 , and 6 of this glucosamine unit could be involved in the epitope since this glucosamine substructure remains unmodified during the nitrous deamination of this residue, leading to 2,5-anhydromannose.

Whereas the inability of $\mathrm{mAbs} \mathrm{D} 7$ and 60.5 to react with LPS BpA100 can be easily ascribed to the absence of the corresponding epitopes, the inability of $\mathrm{mAb}$ P1P3 to react with this LPS (Fig. 3b) was unexpected. A similar absence of reactivity with LPS BpA100 was also systematically observed with sera from mice immunized with LPS Bp1414 (Fig. 2). This may suggest that the 'core' of the LPS from the variant strain A 100 of B. pertussis could be different from that of the more conventional, vaccine strain 1414. However, in a previous study (Caroff et al., 1990 ), we established that the only detectable difference in the polysaccharide fragments isolated from LPS Bp1414 and LPS BpA100 after HF treatment and mild acid hydrolysis was a loss of the distal trisaccharide in the latter, which suggests that the 'cores' of the HF-treated 
LPSs are identical. This observation prompted us to examine the influence of HF treatment on the antigenicity of the LPS. We found that HF/LPS-BpA100 was recognized by P1P3 (Fig. 5). This could indicate that the LPS of this variant strain of $B$. pertussis carries an HFlabile substituent in its core region. Structural analyses should soon shed light on this point.

Regarding the immunogenicity of $B$. pertussis LPS substructures, the observation that sera from some mice immunized with this LPS did not react with the $B$. bronchiseptica LPS (Fig. 2) indicates that the epitopes recognized by P1P3 and 60.5 are less immunogenic than that detectable with $\mathrm{D} 7$. The observation that none of these sera could interact with the LPS from the B. pertussis A100 strain (Fig. 2), and that we were unable to obtain a $\mathrm{mAb}$ that recognized the NA/LPS Bp1414, shows that the carbohydrate region proximal to lipid A is very poorly immunogenic.

The anti- $B$. pertussis mAbs produced in this study, in addition to the anti- $B$. parapertussis and anti- $B$. bronchiseptica mAbs prepared previously (Le Blay et al., 1994), represent an efficient tool for routine identification of these organisms in clinical isolates, as well as for the detection of variations in the LPS components of these bacteria. It is noteworthy that these clinical applications of the mAbs should be much easier if the conclusions drawn from the present study, in which experiments were carried out with isolated LPSs, could be extended to LPS in its natural environment, where it is exposed on the surface of intact organisms. It is clear that this situation can modify the accessibility of certain LPS epitopes, and thus limit the use of the corresponding antibodies. Experiments designed to analyse the interactions of the mAbs with intact organisms are now planned.

\section{ACKNOWLEDGEMENTS}

This work was supported by the Centre National de la Recherche Scientifique (Mission des Relations Internationales). We would like to thank Dr D. Charon for the preparation of the cysteamine-linked $N$-acetylglucosamine.

\section{REFERENCES}

Ackers, J. P. \& Dolby, J. M. (1972). The antigen of Bordetella pertussis that induces bactericidal antibody and its relationship to protection in mice. J Gen Microbiol 70, 371-382.

Archambault, D., Rondeau, P., Martin, D. \& Brodeur, B. R. (1991). Characterization and comparative bactericidal activity of monoclonal antibodies to Bordetella pertussis lipo-oligosaccharide A. J Gen Microbiol 137, 905-911.

Avrameas, S. (1969). Coupling of enzymes to proteins with glutaraldehyde. Use of the conjugates for the detection of antigens and antibodies. Immunochemistry 6, 43-52.

Caroff, M. \& Karibian, D. (1990). Several uses of isobutyric acidammonium hydroxide solvent in endotoxin analysis. Appl Environ Microbiol 56, 1957-1959.

Caroff, M., Tacken, A. \& Szabo, L. (1988). Detergent accelerated hydrolysis of bacterial endotoxins and determination of the anomeric configuration of the glycosyl-phosphate present in the 'isolated Lipid A' fragment of the Bordetella pertussis endotoxin. Carbobydr Res 175, 273-282.

Caroff, M., Chaby, R., Karibian, D., Perry, M., Deprun, C. \& Szabo, L. (1990). Variations in the carbohydrate regions of Bordetella pertussis lipopolysaccharides: electrophoretic, serological and structural features. J Bacteriol 172, 1121-1128.

Chaby, R. \& Caroff, M. (1988). Lipopolysaccharides of Bordetella pertussis endotoxin. Pathogenesis and Immunity in Pertussis, pp. 247-271. Edited by A. C. Wardlaw \& R. Parton. Chichester: John Wiley.

Deprun, C., Karibian, D. \& Caroff, M. (1993). Analysis by ${ }^{252} \mathrm{Cf}$ Plasma Desorption Mass Spectrometry of Bordetella pertussis endotoxin after nitrous deamination. Int J Mass Spectr Ion Process 126, 187-190.

Di Fabio, J. L., Caroff, M., Karibian, D., Richards, J. C. \& Perry, M. B. (1992). Characterization of the common antigenic lipopolysaccharide O-chains produced by Bordetella bronchiseptica and Bordetella parapertussis. FEMS Microbiol Lett 97, 275-282.

Frank, D. W. \& Parker, C. D. (1984). Isolation and characterization of monoclonal antibodies to Bordetella pertussis. J Biol Stand 12, 353-365.

Girard, R. \& Chaby, R. (1985). Inhibition of lipopolysaccharide mitogenicity with characterized anti-lipid A monoclonal antibodies. Immunology 56, 481-487.

Gustafsson, B., Lindquist, U. \& Andersson, M. (1988). Production and characterization of monoclonal antibodies directed against Bordetella pertussis lipopolysaccharide. J Clin Microbiol 26, 188-193.

Johnson, K. G. \& Perry, M. B. (1976). Improved techniques for preparation of bacterial lipopolysaccharides. Can J Microbiol 22, 29-34.

Lebbar, S., Caroff, M., Szabo, L., Merienne, C. \& Szilagyi, L. (1994). Structure of a hexasaccharide proximal to the hydrophobic region of lipopolysaccharides present in Bordetella pertussis endotoxin preparations. Carbobydr Res 259, 257-275.

Le Blay, K., Caroff, M., Richards, J. C., Perry, M. B. \& Chaby, R. (1994). Specific and cross-reactive monoclonal antibodies to Bordetella parapertussis and Bordetella bronchiseptica lipopolysaccharides. Microbiology 140, 2459-2465.

Le Dur, A., Chaby, R. \& Szabo, L. (1980). Isolation of two proteinfree and chemically different lipopolysaccharides from Bordetella pertussis phenol-extracted endotoxin. J Bacteriol 143, 78-88.

Lee, R. T. \& Lee, Y. C. (1974). Synthesis of 3-(2-aminoethylthio)propyl glycosides. Carbobydr Res 37, 193-201.

Li, Z. M., Cowell, J. L., Brennan, M. J., Burns, D. L. \& Manclark, C. R. (1988). Agglutinating monoclonal antibodies that specifically recognize lipooligosaccharide A of Bordetella pertussis. Infect Immun 56, 699-702.

Lipkin, D., Phillips, B. E. \& Abrell, J. W. (1969). The action of hydrogen fluoride on nucleotides and other esters of phosphorus(V) acids. J Org Chem 34, 1539-1547.

Martin, D., Peppler, M. S. \& Brodeur, B. R. (1992). Immunological characterization of the lipooligosaccharide B band of Bordetella pertussis. Infect Immun 60, 2718-2725.

Mountzouros, K. T., Kimura, A. \& Cowell, J. L. (1992). A bactericidal monoclonal antibody specific for the lipooligosaccharide of Bordetella pertussis reduces colonization of the respiratory tract of mice after aerosol infection with $B$. pertussis. Infect Immun 60, $5316-5318$

Nowinsky, R. C., Lostrom, M. E., Tam, M. R., Stone, M. R. \& Burnette, W. N. (1979). The isolation of hybrid cell lines producing monoclonal antibodies against the p15 (E) protein of ecotropic murine leukemia viruses. Virology 93, 111-126. 
Peppler, M. S. (1984). Two physically and serologically distinct lipopolysaccharide profiles in strains of Bordetella pertussis and their phenotype variants. Infect Immun 43, 224-232.

Roy, R., Katzenellenbogen, E. \& Jennings, H. J. (1984). Improved procedures for the conjugation of oligosaccharides to protein by reductive amination. Can J Biochem Cell Biol 62, 270-275.

Sharon, N. \& Lis, H. (1972). Lectins : cell-agglutinating and sugarspecific proteins. Science 177, 949-959.
Terashima, M., Uezumi, I., Tomio, T., Kato, M., Irie, K., Okuda, T., Yokota, S. \& Noguchi, H. (1991). A protective human monoclonal antibody directed to the outer core region of Pseudomonas aeruginosa lipopolysaccharide. Infect Immun 59, 1-6.

Received 31 August 1995; revised 4 January 1996; accepted 29 January 1996. 